\title{
Developing a hybrid, carbon/glass fiber-reinforced, epoxy composite automotive drive shaft
}

\begin{abstract}
In this study, a finite element analysis was used to design composite drive shafts incorporating carbon and glass fibers within an epoxy matrix. A configuration of one layer of carbon-epoxy and three layers of glass-epoxy with $0^{\circ}, 45^{\circ}$ and $90^{\circ}$ was used. The developed layers of structure consists of four layers stacked as [+45glass $\%-45$ glass $^{\circ} / 0$ carbon $^{\circ} / 90$ glass $^{\circ}$ ]. The results show that, in changing carbon fibers winding angle from $0^{\circ}$ to $90^{\circ}$, the loss in the natural frequency of the shaft is $44.5 \%$, while, shifting from the best to the worst stacking sequence, the drive shaft causes a loss of $46.07 \%$ in its buckling strength, which represents the major concern over shear strength in drive shaft design.
\end{abstract}

